\title{
Selection of a sensitive material for the detection of explosive, application to the detection of traces of TNT
}

\author{
Myriam Bouhadid, Florian Veignal, Eric Pasquinet, Céline Frenois, Sarah Goléo, Christelle Barthet \\ and Pierre Montméat \\ CEA, DAM, LE RIPAULT, F-37260, MONTS, FRANCE \\ myriam.bouhadid@cea.fr
}

\begin{abstract}
:
For the development of fluorescent sensors, one of the key points is choosing the sensitive material. Here, we aim at evaluating, under strictly identical experimental conditions, the performance of three materials for the detection of dinitrotoluene (a volatile marker of trinitrotoluene) through various parameters: response time, fluorescence intensity, sensitivity, reversibility, reaction after successive exposures and long-term stability. This first study rendered it possible to select a conjugated molecule as the best sensitive material for the development of a lab-made prototype. In a second part, the material is used for the detection of vapours emitted from swabs tainted with TNT.
\end{abstract}

Key words: Detection, explosives, fluorescent material, chemical sensors, sampling

\section{Introduction}

The increased use of explosives in terrorist activities has created a demand for a continued innovation in the detection of these agents. To this aim, the detection of nitroaromatic compounds (NAC) using chemical sensors has been the major goal of our team for almost a decade. Fluorescent sensors especially seem to satisfy requirements in terms of reliability, cost and handling ability. In this field, an optical device based on the capability of various materials to detect explosives vapours, particularly nitroaromatics compounds such as trinitrotoluene TNT and dinitrotoluene DNT, has been developed [1]. TNT is one of the most commonly used explosives for military applications and DNT has a significant part in the chemical signature of this target compound [2].

The goal of this paper is first to select a fluorescence sensitive material adapted for the detection of nitroaromatic explosive vapours. Three various materials have been first selected (cf. Tab. 1). In the second part of this study, the selected material is used for the detection of ultra-traces of TNT. The detection of explosive is often performed from swabs tainted with particles of explosives on their surface[3-5]. In order to evaluate the sensitivity of our fluorescent sensor in such conditions, an oven has been developed to desorb vapours from swabs and transport them to the sensor.

\section{Experimental part}

Fluorescent prototype:

The prototype used for the detection by fluorescence is presented in Fig. 1. It has been described in detail elsewhere [6].

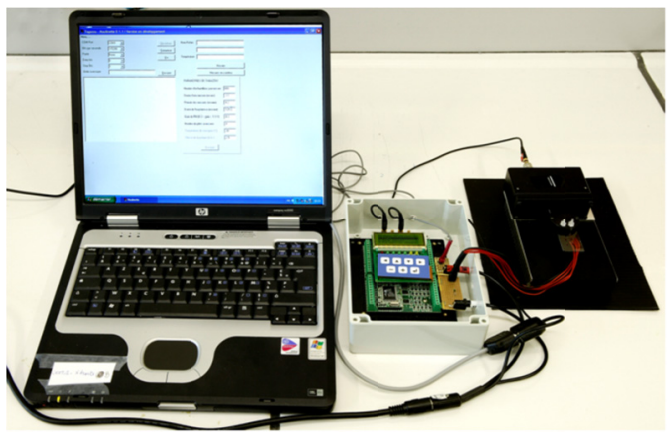

Fig. 1: Photography of the fluorescent detector

For the fluorescence measurements, each material was deposited on the entire surface of a glass substrate (microscope slides, $75 \mathrm{~mm} \times 25 \mathrm{~mm} \times 1 \mathrm{~mm}$ ) by spin-coating (Braive Instrument's spin-coater at $600 \mathrm{rpm}$ ) from a chloroform solution during $60 \mathrm{~s}$ of drying. The concentrations were determined in order for the fluorescence signal to be contained between 3 and $10 \mathrm{~V}$ in the prototype.

\section{Description of the sensors tests:}

The three materials were evaluated for the detection of vapours under dry synthetic air and real ambient air. During a typical experiment, the material was exposed to air (synthetic or ambient), organic vapours diluted in air 
(synthetic or ambient) for $10 \mathrm{~min}$ and then to air again (synthetic or ambient) with a flow rate of $20 \mathrm{~L} / \mathrm{h}$

\section{Description of the oven and the tests with swabs:}

The oven is shown in Fig. 2. Swabs were elaborated from pieces of PTFE.

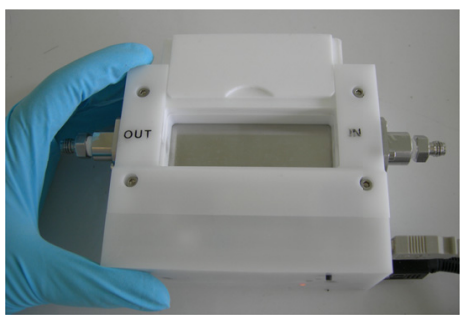

Fig. 2: Photography of the oven
The swab tainted with explosive was elaborated as followed: $10 \mu \mathrm{L}$ of a solution of TNT in acetone were dropped on the surface of the PTFE and then dried. The experiments of detection have consisted in recording the response of the sensors when exposed to the vapor of the swab when heated at $140{ }^{\circ} \mathrm{C}$ in the oven. The flow rate was $20 \mathrm{~L} / \mathrm{h}$.

\section{Choice of the best sensitive material}

The design of a sensor requires several steps. One of the key points is the choice of the sensitive material. Here, we first evaluate, in strictly identical conditions, various performance parameters of the three materials [7-9] (cf. Tab. 1) for the detection of DNT as a volatile impurity of TNT: fluorescence intensity, response time, sensitivity, reversibility, reaction after successive exposures and long term stability.

Tab. 1 : Presentation of the three fluorescent materials [8-10] studied in this work

\begin{tabular}{|l|l|l|l|}
\hline Sensitive material & Chemical structure & Nature & Nain characteristics \\
\hline \hline $\begin{array}{l}\text { Material 1: } \\
\pi \text {-conjugated phenylene-ethylene diimine }\end{array}$ & Sorous, $\pi$-conjugated \\
\hline $\begin{array}{c}\text { Material 2: } \\
\text { polypentiptycene }\end{array}$ & Solid polymer & $\begin{array}{c}\text { Porous, } \pi \text {-conjugated, fluorescent } \\
\text { quenching amplification effect }\end{array}$ \\
\hline $\begin{array}{c}\text { Material 3: } \\
\text { fluorescent polycarbosilane }\end{array}$ & Viscous liquid polymer & $\begin{array}{c}\text { Viscoelatic properties, high gas } \\
\text { permittivity }\end{array}$ \\
\hline
\end{tabular}

To demonstrate the feasibility of the fluorescent sensor, each material was first tested in the presence of DNT $\left(30 \mathrm{ppb}_{\mathrm{v}}\right)$. The obtained detection signals are shown in Fig. 3.

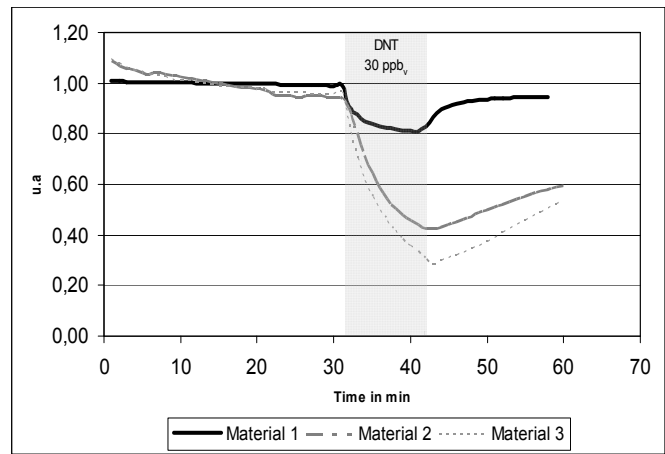

Fig. 3: Example of signal detection by fluorescence upon exposure to $30 \mathrm{ppbv}$ of DNT for $10 \mathrm{~min}$
All the previous criteria are shown in Tab. 2, a ranking of the materials was proposed. Material 2 was very sensitive but the intensity of fluorescence as well as the reversibility was poor. Material 3 was also very sensitive, but the response time as well as the reversibility was far from optimal. Material 1 enabled a safe and reproducible detection since this material exhibited the best reversibility. Its only drawback concerned the weaker sensitivity compared to materials 2 and 3 . Nevertheless, the limit of detection was estimated at ca $12 \mathrm{ppb}_{\mathrm{v}}$, which was sufficient for our application. The excellent reversibility led to a long-term stability of the sensor and thus reduced the maintenance cost of the detector. For this reason, material 1 was selected for further investigations. 


\begin{tabular}{|c|c|c|c|}
\hline \multirow{2}{*}{ Performances } & \multicolumn{3}{|c|}{ ranking } \\
\cline { 2 - 4 } & Material 1 & Material 2 & Material 3 \\
\hline Intensity of fluorescence & +++ & + & ++ \\
\hline Response time & +++ & ++ & +++ \\
\hline Response amplitude & + & +++ & +++ \\
\hline Linearity of the response for low concentration & +++ & ++ & ++ \\
\hline Reversibility & +++ & ++ & ++ \\
\hline \hline Behavior after several exposures & +++ & + & ++ \\
\hline Global performances & +++ & + & ++ \\
\hline
\end{tabular}

Tab. 2 : Performances summary with ranking of materials

\section{Application to the detection of traces of TNT}

We have checked that no signal was observed when the previous procedure was applied to:

- The oven with $10 \mu \mathrm{g}$ onto a swab ( $\mathrm{T}=$ room temperature)

- The oven with a swab cleaned with acetone $\left(T=140^{\circ} \mathrm{C}\right)$

A typical response obtained with $10 \mu \mathrm{g}$ of TNT is shown in Fig. 4. The decrease of the fluorescence was very large and significant. We could notice that the reversibility was poor. The oven was thus well-adapted to extract vapours from a tainted swab.

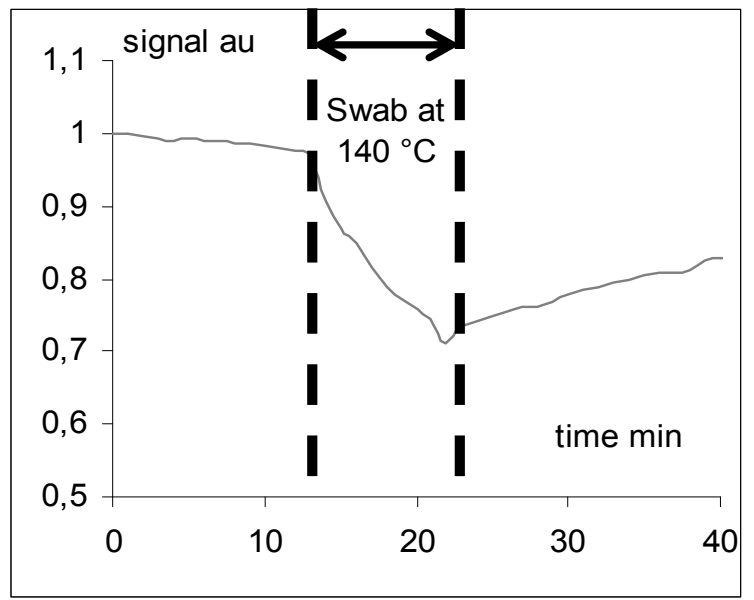

Fig. 4: Response of the sensors to $10 \mu \mathrm{g}$ of TNT

Fig. 5 represents the average percentage of fluorescence quenching we obtained for several amounts of TNT, each bar is representative of 4 different experiments performed with various swabs and various sensitive films. A reliable detection occurred when the percentage was up to $7.5 \%$ [6]. Thus, the limit of detection of the sensor was closed to $500 \mathrm{ng}$.

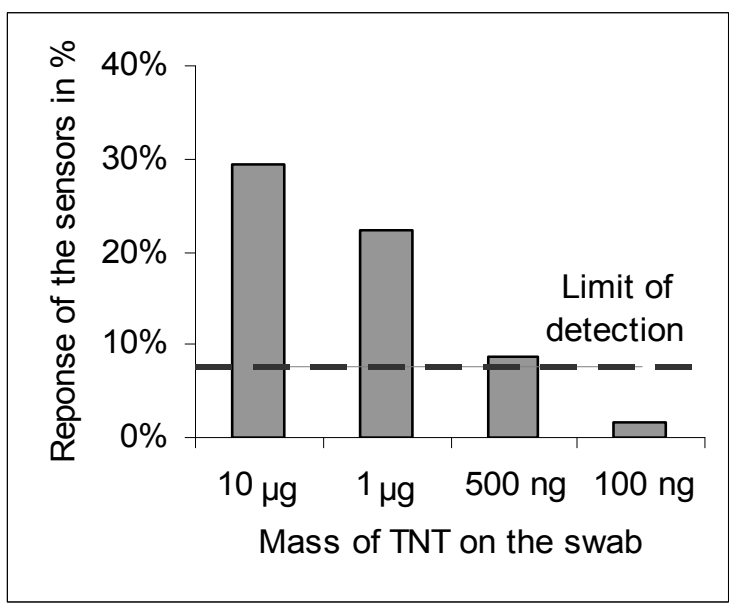

Fig. 5: Responses of the sensors to various mass of TNT

\section{Conclusion}

One of the objectives of our research group is to develop a fluorescence detection prototype [1] which detects vapors from nitroaromatic compounds. In this context, the present study concerning the choice of the best sensitive material was realized. The three materials selected for their various structures presented large responses towards DNT. Nevertheless, only the $\pi$-conjugated phenylene-ethynylene diimine conjugated exhibited an excellent reversibility, which conferred a large advantage to this material rendering possible its use without servicing or calibration between two exposures. Moreover, the performances of this chemical were in line with our objectives in terms of fluorescence intensity, response time, sensitivity and selectivity. It was also shown to be an efficient sensitive material for the detection of ultra-traces of TNT. The sensor has detected vapors of TNT emitted from the thermal desorption of a tainted swab. The sensitivity was closed to $500 \mathrm{ng}$ of TNT. 


\section{Acknowledgements}

The authors wish to thank Thomas Caron, Françoise Serein-Spirau and Jean-Pierre LèrePorte for their help in developing of the material 1.

\section{References}

[1] T. Caron, S. Clavaguera, M. Huron, P Montméat, E. Pasquinet, J. P. Lère-Porte, F. Serein-spirau, F. Perraut, and P. Prené, Chemical Engineering Transactions 23, 2530 (2010); doi: 10.3303/CET1023005

[2] P. A. Pella, J. Chem. Thermodynamics 9, 301-305 (1977); doi: 10.1016/00215614(77)90049-0

[3] D. Perret, S. Marchese, R. Gentili, R. Curini, A. Terracciano, E. Bafile, and F. Romolo, 68, (2008); doi: 10.1365/s10337-008-0746-8

[4] A. Popov, H. Chen, and O. Kharybin, Chemical Communication 15, 1953-1955 (2005); doi: 10.1039/b419291
[5] J. Yinon, "Forensic and Environmental detection of explosives, Chap. 2," ed: wiley, 1999.

[6] T. Caron, M. Guillemot, P. Montméat, F. Veignal, F. Perraut, P. Prené, and F. Serein-spirau, Talanta 81, 543-548 (2010); doi: 10.1016/j.talanta.2009.12.040

[7] J. S. Yang and T. M. Swager, Journal American Chemical Society 120, 5321-5322 (1998); doi: 10.1021/ja9742996

[8] E. Pasquinet, P. Montméat, L. Hairault, R. Amedee, F. Guida, B. Boutevin, and F. Ganachaud, France Patent FR2929283 (2009).

[9] S. Clavaguera, O. Dautel, L. Hairault, C. Méthivier, P. Montméat, E. Pasquinet, C. M. Pradier, F. Serein-spirau, S. Wakim, F. Veignal, J. Moreau, and J. P. Lère-Porte, Journal of Polymer Science, Part A, Polymer Chemistry 47, 4141-4149 (2009); doi: $10.1002 /$ pola.23474

[10] J. S. Yang and T. M. Swager, Journal American Chemical Society 120, 1186411873 (1998); doi: 10.1021/ja982293q 